\title{
Safety of Living Kidney Donation: Another Brick in the Wall...and a Solid (Physiologic) One
}

\section{Related Article, p. 114}

$\mathbf{K}^{\mathrm{i}}$ idney donation is a meaningful act for the donor, both psychologically and physiologically. As nephrologists, it is our responsibility to give donors the best guarantees that this generous act will be as safe as possible. ${ }^{1}$ The short-term risk for morbidity or mortality after kidney donation is very low and inherent to every surgical procedure. ${ }^{1,2}$ Numerous studies have also demonstrated the short-term physiologic consequences of kidney donation in terms of glomerular filtration rate (GFR), namely a rapid compensatory hypertrophy of the remaining kidney. Consequently, in young donors, GFRs soon after unilateral nephrectomy are $60 \%$ to $70 \%$ of those before donation. $^{1,3}$

The potential major problems with kidney donation are long-term consequences, such as the risk of developing chronic kidney disease (CKD), including end-stage renal disease (ESRD). Epidemiologic data have recently revived the debate about the safety of kidney donation by showing an increased relative risk of ESRD in kidney donors compared with matched controls. ${ }^{4,5}$ However, this must be interpreted in light of the quite small absolute risk. ${ }^{6}$ Moreover, these studies, even those including controls, are retrospective and have been criticized. ${ }^{6,7}$ Thus, these worrisome reports are not yet sufficient to dampen living kidney donation programs, a fact acknowledged by their authors. ${ }^{5}$

However, doubt exists, and so the study by Kasiske et $\mathrm{al}^{8}$ in this issue of $A J K D$ is an important one. The authors show physiologic data from living kidney donors over 3 years of follow-up; hence, unlike most prior data, the new study is more physiologic than epidemiologic. ${ }^{8}$ The study has 3 main methodological strengths. First, the design was prospective and controlled (with donors paired to controls), whereas most other studies were either retrospective and/or without appropriate controls. ${ }^{1,9-12}$ Second, blood pressure changes postdonation were assessed by the gold standard of ambulatory blood pressure monitoring. Third, and of prime interest, the authors measured GFR, by plasma iohexol clearance.

Equations for calculating estimated GFR (eGFR) ${ }^{13,14}$ have limitations and the precision (at the individual level) of any equation is probably not sufficient, especially at high GFRs. ${ }^{13}$ Also, the ability of eGFR to evaluate the measured GFR (mGFR) slope over time remains questionable, particularly at high GFRs. ${ }^{3,15,16}$ More generally, we still believe that mGFR has a role in clinical research in nephrology, particularly when GFR is considered as a primary end point. ${ }^{13}$ Reference methods are often described as cumbersome and costly. However, plasma clearances are far simpler to do than urinary clearances even if they are time consuming (at least 4 or 5 hours). ${ }^{17}$ Moreover, in Europe, the cost for one GFR measurement is $\sim \$ 200$, which seems acceptable for a reference method, especially compared with prices of other "references" in medicine, such as a computed tomographic scan in pulmonology or an echocardiogram in cardiology.

The iohexol mGFR data shown by Kasiske et al are reassuring. The authors observed a significant increase in mGFR, with the mean value going from $74 \pm 13 \mathrm{~mL} / \mathrm{min}$ at 6 months to $78 \pm 14 \mathrm{~mL} / \mathrm{min}$ at 3 years. ${ }^{8}$ The increase in mGFR at 3 years might be viewed positively, indicating that uninephrectomy does not accelerate age-related decline in GFR, at least for the first 3 years of follow-up. A more pessimistic view is that the mGFR increase could be a detrimental "hyperfiltration status" because single-nephron GFR is undoubtedly increased in the remaining kidney. ${ }^{7}$ In other words, mGFR of $78 \mathrm{~mL} / \mathrm{min}$ for one kidney could correspond to $\mathrm{mGFR}$ of $156 \mathrm{~mL} / \mathrm{min}$ in 2 functioning kidneys. ${ }^{18}$ In this scenario, the 3-year follow-up is too limited because adverse events (ie, decreased GFR) would occur later, as observed in other hyperfiltering states such as type 1 diabetes or obesity. ${ }^{10,15,18}$ In this context, the potential adverse effects of partial ablation of nephron mass in individuals having a low nephron endowment at birth, as noted by Brenner and Mackenzie almost 2 decades ago, needs to be taken into consideration, ${ }^{19,20}$ especially because the Kasiske et al article has no information on birth weight (and thereby nephron endowment) of the donors in this study. Whether this "hyperfiltration theory" explains the higher ESRD risk in recent retrospective studies is debated. ${ }^{4,5}$ First, hyperfiltration after kidney donation could differ pathophysiologically from hyperfiltration secondary to diabetes and obesity. Recent physiologic data have demonstrated that postnephrectomy hyperfiltration is attributable to hyperperfusion and

\footnotetext{
Address correspondence to Pierre Delanaye, MD, PhD, Service de Dialyse, CHU Sart Tilman, 4000 Liège, Belgium. E-mail: pierre_delanaye@yahoo.fr

(C) 2015 by the National Kidney Foundation, Inc. $0272-6386$

http://dx.doi.org/10.1053/j.ajkd.2015.04.005
} 
renocortical hypertrophy, with no features suggesting glomerular capillary hypertension. ${ }^{7}$ Second, hyperfiltration is certainly not the unique pathologic process. De novo kidney diseases might also account for the higher risk of CKD. ${ }^{5,12,21}$ One study found that most living kidney donors developing ESRD were members of the recipient's family (with common genetic background) and had immunologically mediated glomerulonephritis; no case of segmental glomerulosclerosis was observed. ${ }^{5}$

The blood pressure and glucose metabolism results presented by Kasiske are very reassuring. Even with statistical differences between donors and controls, the urinary albumin-creatinine ratio (UACR) findings are favorable, with a very small, clinically not relevant, increase in UACR after 3 years (from 3.6 [interquartile range (IQR), 2.4-5.8] to 4.2 [IQR, 2.7-7.1] $\mathrm{mg} / \mathrm{g}){ }^{8}$ Although a substantial decline in UACR after uninephrectomy might have been expected, the compensatory increase in single-nephron GFR postuninephrectomy with some changes in glomerular albumin permeability and/or tubular albumin reabsorption might explain the observed slight increase. Overinterpretation of the results of Kasiske et al with respect to the impact of uninephrectomy on albuminuria should be avoided. These findings also do not preclude the later development of de novo kidney disease (such as diabetes). ${ }^{21}$

More intriguing are the parathyroid hormone (PTH), phosphorus, homocysteine, and uric acid results, which significantly differ between the 2 groups. $^{8}$ Regarding higher PTH and lower phosphorus values in donors, it would have been interesting to measure calcidiol, calcitriol, and fibroblast growth factor 23 (FGF-23). FGF-23 measurements would be of great interest because it has been suggested that this phosphaturic hormone is the first to be abnormally "hypersecreted" in early CKD stages, including after kidney donation. ${ }^{22,23}$ Increased FGF-23 secretion could lead to increased phosphaturia, inhibition of $1 \alpha$-hydroxylase, and a decrease in calcitriol levels, which would also lower intestinal reabsorption of both phosphorus and calcium. Calcemia is maintained at a normal concentration by an increase in PTH secretion, which itself promotes phosphaturia and $1 \alpha$-hydroxylase activity. ${ }^{23}$ The data from Kasiske et al do not confirm or reject this hypothetical scenario. Also, PTH and phosphorus concentrations are in the reference range for most patients. ${ }^{8}$ Also reassuring is that the increase in PTH concentration observed at 6 months is not different after 3-year follow-up, suggesting that a new steady state is reached. ${ }^{24}$

The increase in donors' uric acid concentrations (to $5.5 \mathrm{mg} / \mathrm{dL}$ after 3 years vs $5.0 \mathrm{mg} / \mathrm{dL}$ in controls) is also of interest. As acknowledged by the authors, the significance of this change on risk of nephrolithiasis, gout, or CKD progression cannot be determined. We should also recognize that it remains unclear if uric acid is a cause or consequence of CKD, an uncertainty that also applies to the potential increased cardiovascular risk due to hyperhomocysteinemia and uric acid. $^{25,26}$ However, as remarked by Kasiske et al, mere association is not causality. Interventional studies to decrease homocysteine levels have failed to show cardiovascular benefit. ${ }^{27}$ More importantly, unquestionable risk factors such as hypertension and hypercholesterolemia are similar during follow-up of the 2 groups. Moreover, most observational retrospective studies in living kidney donors have not detected additional cardiovascular risk or mortality. $2,11,28-30$

Methodological strengths make the study presented by Kasiske et al of outstanding interest. However, these reassuring short-term results only apply to relatively young white nonobese donors. Less optimistic data, even if methodologically less solid, have recently underlined the potential risk of living donation in African American (in particular those with risk alleles at the APOL1 locus) ${ }^{31-33}$ and obese patients. $^{11,34}$ It must be emphasized that only healthy individuals were included in the Kasiske et al study. In clinical practice, individuals with minimal proteinuria, not well-controlled hypertension, or marked obesity are sometimes accepted for living kidney donation. ${ }^{35}$ From our point of view, this practice is very questionable.

There is no doubt that continuing this type of physiologic study for 5 or 10 years would be of great value, with the potential of documenting hard end points such as CKD stage 3b, ESRD, or cardiovascular events. Pending results of such long-term follow-up studies, a balanced well-informed decision is possible in most situations involving potential living kidney donation. We suggest that with caveats, living kidney donation is reasonably safe. In all cases, and because prudence and caution is the least we can offer (primum non nocere), we believe that careful evaluation (including documentation of birth weight), education, and long-term medical follow-up should be kept in mind when considering living donors. $^{36}$

\author{
Pierre Delanaye, $M D, P^{1}$ \\ Christophe Mariat, $M D, P^{2}$ \\ Richard J. Glassock, $M^{3}$ \\ ${ }^{1}$ University of Liège, Liège, Belgium \\ ${ }^{2}$ University Jean Monnet, Saint-Etienne, France \\ ${ }^{3}$ UCLA, Los Angeles, California
}

\section{ACKNOWLEDGEMENTS}

Support: None.

Financial Disclosure: The authors declare that they have no relevant financial interests. 


\section{REFERENCES}

1. Delanaye P, Weekers L, Dubois BE, et al. Outcome of the living kidney donor. Nephrol Dial Transplant. 2012;27(1):41-50.

2. Segev DL, Muzaale AD, Caffo BS, et al. Perioperative mortality and long-term survival following live kidney donation. JAMA. 2010;303(10):959-966.

3. Barri YM, Parker T III, Daoud Y, Glassock RJ. Definition of chronic kidney disease after uninephrectomy in living donors: what are the implications? Transplantation. 2010;90(5):575-580.

4. Muzaale AD, Massie AB, Wang MC, et al. Risk of end-stage renal disease following live kidney donation. JAMA. 2014;311(6): 579-586.

5. Mjoen G, Hallan S, Hartmann A, et al. Long-term risks for kidney donors. Kidney Int. 2014;86(1):162-167.

6. Gill JS, Tonelli M. Understanding rare adverse outcomes following living kidney donation. JAMA. 2014;311(6):577-579.

7. Lenihan CR, Busque S, Derby G, Blouch K, Myers BD, Tan JC. Longitudinal study of living kidney donor glomerular dynamics after nephrectomy. J Clin Invest. 2015;125(3):1311-1318.

8. Kasiske BL, Anderson-Haag T, Israni AK, et al. A prospective controlled study of living kidney donors: three-year follow-up. Am J Kidney Dis. 2015;66(1):114-124.

9. Saran R, Marshall SM, Madsen R, Keavey P, Tapson JS, Long-term follow-up of kidney donors: a longitudinal study. Nephrol Dial Transplant. 1997;12(8):1615-1621.

10. Fehrman-Ekholm I, Kvarnstrom N, Softeland JM, et al. Post-nephrectomy development of renal function in living kidney donors: a cross-sectional retrospective study. Nephrol Dial Transplant. 2011;26(7):2377-2381.

11. Ibrahim HN, Foley R, Tan L, et al. Long-term consequences of kidney donation. N Engl J Med. 2009;360(5):459-469.

12. Kaplan B, Ilahe A. Quantifying risk of kidney donation: the truth is not out there (yet). Am J Transplant. 2014;14(8):1715-1716.

13. Delanaye P, Mariat C. The applicability of eGFR equations to different populations. Nat Rev Nephrol. 2013;9(9):513-522.

14. Levey AS, Stevens LA, Schmid CH, et al. A new equation to estimate glomerular filtration rate. Ann Intern Med. 2009;150(9):604-612.

15. de Boer IH, Sun W, Cleary PA, et al. Longitudinal changes in estimated and measured GFR in type 1 diabetes. J Am Soc Nephrol. 2014;25(4):810-818.

16. Gaspari F, Ruggenenti P, Porrini E, et al. The GFR and GFR decline cannot be accurately estimated in type 2 diabetics. Kidney Int. 2013;84(1):164-173.

17. Gaspari F, Perico N, Matalone M, et al. Precision of plasma clearance of iohexol for estimation of GFR in patients with renal disease. J Am Soc Nephrol. 1998;9(2):310-313.

18. Cachat F, Combescure C, Cauderay M, Girardin E, Chehade H. A systematic review of glomerular hyperfiltration assessment and definition in the medical literature. Clin J Am Soc Nephrol. 2015;10(3):382-389.

19. Luyckx VA, Bertram JF, Brenner BM, et al. Effect of fetal and child health on kidney development and long-term risk of hypertension and kidney disease. Lancet. 2013;382(9888): 273-283.

20. Brenner BM, Mackenzie HS. Nephron mass as a risk factor for progression of renal disease. Kidney Int Suppl. 1997;63:S124-S127.

21. Steiner RW, Ix JH, Rifkin DE, Gert B. Estimating risks of de novo kidney diseases after living kidney donation. Am J Transplant. 2014;14(3):538-544.

22. Olauson H, Vervloet MG, Cozzolino M, Massy ZA, Urena TP, Larsson TE. New insights into the FGF23-klotho axis. Semin Nephrol. 2014;34(6):586-597.

23. Young A, Hodsman AB, Boudville N, et al. Bone and mineral metabolism and fibroblast growth factor 23 levels after kidney donation. Am J Kidney Dis. 2012;59(6):761-769.

24. Garg AX, Pouget J, Young A, et al. Fracture risk in living kidney donors: a matched cohort study. Am J Kidney Dis. 2012;59(6):770-776.

25. Feig DI, Kang DH, Johnson RJ. Uric acid and cardiovascular risk. N Engl J Med. 2008;359(17):1811-1821.

26. Welch GN, Loscalzo J. Homocysteine and atherothrombosis. N Engl J Med. 1998;338(15):1042-1050.

27. Jardine MJ, Kang A, Zoungas S, et al. The effect of folic acid based homocysteine lowering on cardiovascular events in people with kidney disease: systematic review and meta-analysis. BMJ. 2012;344:e3533.

28. Mjoen G, Reisaeter A, Hallan S, et al. Overall and cardiovascular mortality in Norwegian kidney donors compared to the background population. Nephrol Dial Transplant. 2012;27(1): 443-447.

29. Garg AX, Meirambayeva A, Huang A, et al. Cardiovascular disease in kidney donors: matched cohort study. BMJ. 2012;344:e1203.

30. Reese PP, Bloom RD, Feldman HI, et al. Mortality and cardiovascular disease among older live kidney donors. Am J Transplant. 2014;14(8):1853-1861.

31. Lentine KL, Schnitzler MA, Xiao H, et al. Racial variation in medical outcomes among living kidney donors. $N$ Engl J Med. 2010;363(8):724-732.

32. Gibney EM, King AL, Maluf DG, Garg AX, Parikh CR. Living kidney donors requiring transplantation: focus on African Americans. Transplantation. 2007;84(5):647-649.

33. Freedman BI, Kopp JB, Langefeld CD, et al. The apolipoprotein L1 (APOL1) gene and nondiabetic nephropathy in African Americans. $J$ Am Soc Nephrol. 2010;21(9):1422-1426.

34. Nogueira JM, Weir MR, Jacobs S, et al. A study of renal outcomes in obese living kidney donors. Transplantation. 2010;90(9):993-999.

35. Davis CL, Cooper M. The state of US living kidney donors. Clin J Am Soc Nephrol. 2010;5(10):1873-1880.

36. LaPointe RD, Hays R, Baliga P, et al. Consensus conference on best practices in live kidney donation: recommendations to optimize education, access, and care. Am J Transplant. 2015;15(4):914-922. 